\title{
Optimal configuration of a micro-earthquake network
}

\author{
O. Valtonen, M. Uski, A. Korja, T. Tïra, and J. Kortström \\ Institute of Seismology, Department of Geosciences and Geography, University of Helsinki, Finland \\ Correspondence to: O. Valtonen (outi.valtonen@ helsinki.fi)
}

Received: 17 October 2012 - Revised: N.A. - Accepted: 19 October 2012 - Published: 2 May 2013

\begin{abstract}
This study simulates automatic event detection and location performance of a micro-earthquake network centred around a future power plant site in Finland, Fennoscandian Shield. Simulation of the event location capability is based on a relationship derived between event magnitude and maximum detection distance. Azimuthal coverage and threshold magnitude are computed for different station configurations and the results are presented as contour maps.

An optimal configuration of ten seismograph stations is proposed for further on-site survey. The network fulfils the preconditions of automatic event location capability down to $M_{\mathrm{L}} 0.0$ and azimuthal coverage better than $180^{\circ}$ within $25 \mathrm{~km}$ radius from the study site. Annual number of earthquakes $\left(M_{\mathrm{L}} \geq 0.0\right)$ detected by the network is estimated to be 2 and 8 within 25 and $50 \mathrm{~km}$ radius from the power plant site.
\end{abstract}

\section{Introduction}

Sites of vulnerable constructions, such as nuclear power plants, are required to be evaluated for seismic risk and monitored for seismicity (IAEA, 3.30, 2010). When a dense, local seismic network is set up around the site, numerous microearthquakes $\left(M_{\mathrm{L}}<2.0\right)$ are expected to be recorded within a relatively short time period. Local networks provide accurate estimates of seismic source parameters and thus seismotectonic interpretation and seismic hazard evaluation of the area can be improved.

This report searches an optimal configuration for a microearthquake network to be deployed around a future Pyhäjoki nuclear power plant (PNPP) in Finland. Pyhäjoki is situated in the seismically quiet central part of the Fennoscandian Shield (Fig. 1). For improving the tectonic interpretation of the study area numerous earthquakes should be recorded. Due to the low seismic activity rate of the area events larger than $M_{\mathrm{L}} 2.0$ occur rarely, which could be compensated by designing a network that has an ability to detect and locate extremely weak seismic events. Kuusamo local network in the Central Fennoscandian Shield (Fig. 1; Uski et al., 2012), is an example of such a local network where automatic detections of micro-earthquakes smaller than $M_{\mathrm{L}} 0.0$ can be easily gained. We suggest that the PNPP network should have an automatic event location capability down to $M_{\mathrm{L}} 0.0$ or lower. The annual frequency of micro-earthquakes below the current detection threshold $\left(M_{\mathrm{L}} \sim 1.5\right)$ is estimated in this report.

Because the seismotectonics of a near region of a power plant should be well described (IAEA, 3.12, 2010), the network simulations are focused to get good automatic event detection capability and source location precision within $25 \mathrm{~km}$ radius of the PNPP. If the signal-to-noise ratio is sufficiently high to enable automatic identification of signal onsets accurately, the event location performance of a local network is governed by the azimuthal gap (AG, i.e. the largest gap in azimuth between stations seen from the epicentre). For unambiguous determination of focal mechanisms, each of the four azimuthal quadrants should include at least one observation point, i.e. AG should be less than $90^{\circ}$. For good location precision, AG less than $\sim 180^{\circ}$ is adequate (e.g. Uski et al., 2011).

Small AG could be gained by simply surrounding the study area consistently with stations. However, the ideal geometry of the PNPP network is inhibited by the lack of offshore sites, which increases AG. In order to have satisfactory detection and location capability offshore, the network is to be denser at the shoreline. Following the IAEA guidelines, one recording unit is to be operating at the site vicinity. In addition, the nearest permanent station of the Finnish national seismic network (FNSN), at a distance of $29 \mathrm{~km}$ from the PNPP, is included in the network. The locations for the complimentary stations are searched within $50 \mathrm{~km}$ from the site (Fig. 1). 


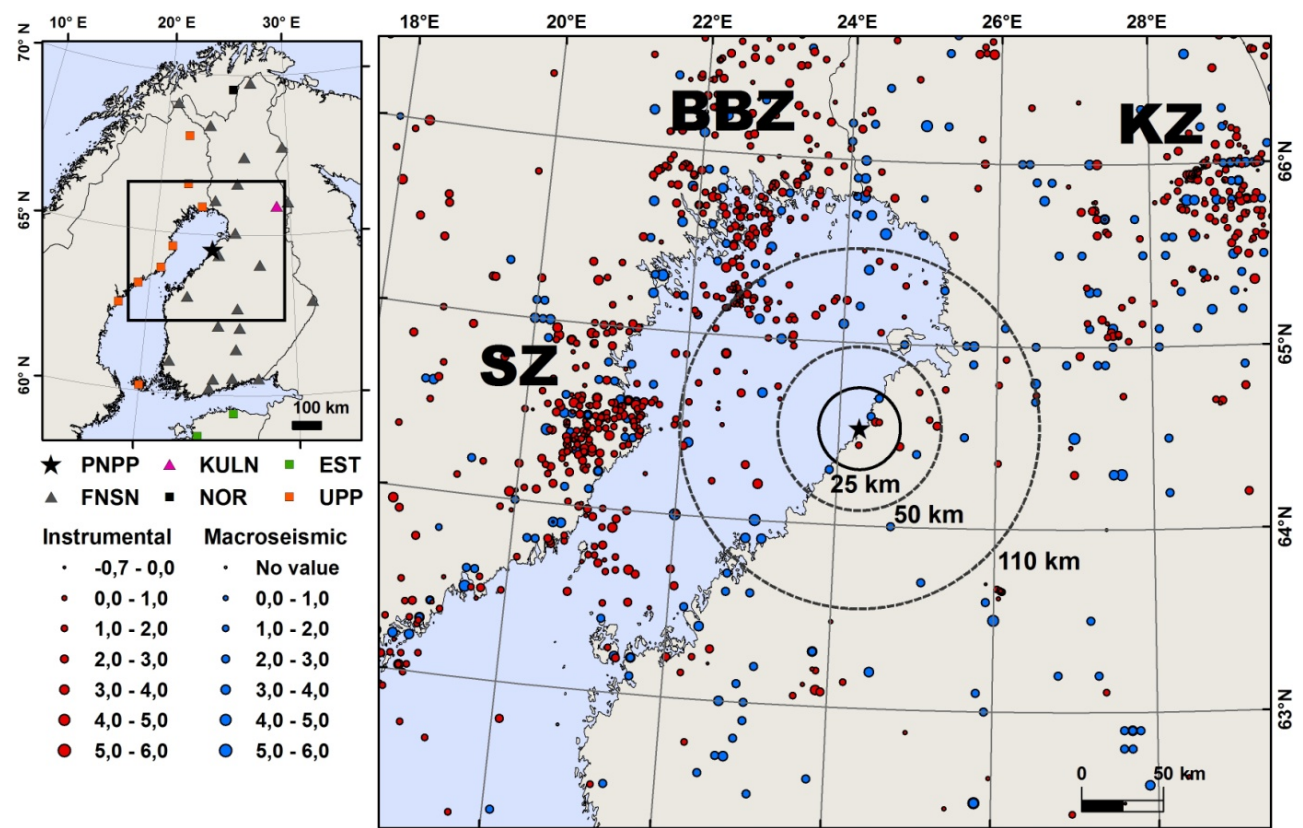

Fig. 1. A seismicity map of the Central Fennoscandia for the time period 1375-2010 (Ahjos and Uski, 1992). Macroseismic (-1970) and instrumental (1971-) epicentres are denoted by blue and red dots, respectively. Concentric circles show the survey area. Seismicity zones: SZ - Skellefte; BBZ - Bothnian Bay-Finnmark; KZ - Kuusamo. Inset map shows the location of seismic stations used in automatic event processing by Institute of Seismology, University of Helsinki (ISUH). Abbreviations: FNSN - Finnish National Seismic Network; KULN Kuusamo Local Network; NOR - ARCES array of Norsar, EST - Estonian seismic stations; UPP - Seismic stations of University of Uppsala.

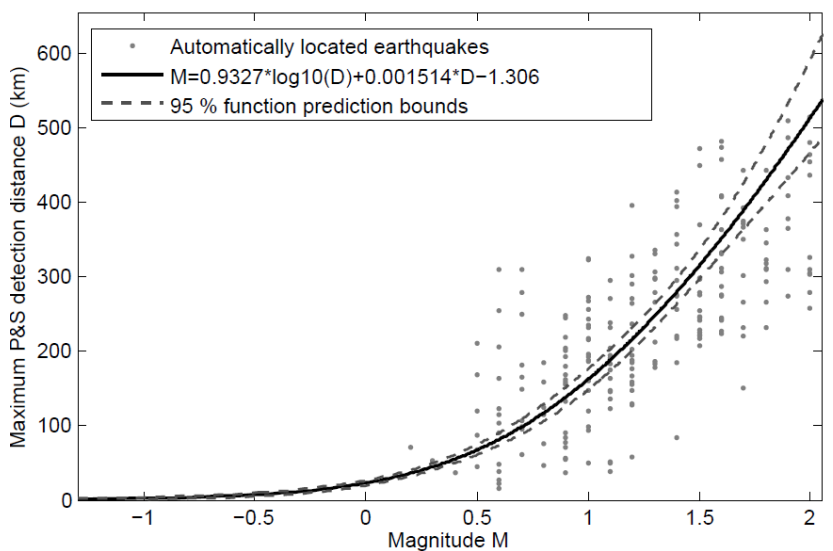

Fig. 2. A calculated fit and the non-simultaneous $95 \%$ function prediction bounds for the relationship between event magnitude and maximum $\mathrm{P}$ - and $\mathrm{S}$-wave pair detection distance.

\section{Data and methods of analysis}

Fully automatic event bulletins published by the Institute of Seismology of the University of Helsinki (ISUH; www. seismo.helsinki.fi/bulletin/list/alert/alertBull.html) are used to simulate the network performance. The data set comprises 259 micro-earthquakes, automatically located by the ISUH (Fig. 1). The data reflect average crustal attenuation characteristic of Central Fennoscandia and it is therefore well suited

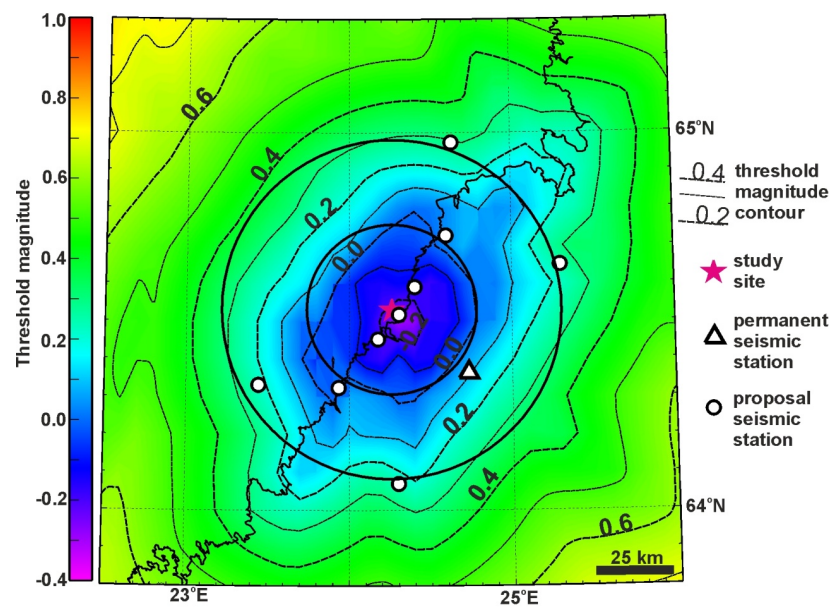

Fig. 3. A map of the threshold magnitude $\left(M_{\mathrm{th}}\right)$ within a ten station network. Note that two offshore stations on small islands increase symmetry and lower the $M_{\text {th }}$ values along the coast and offshore. Concentric circles around the site show the survey area.

for studies in attenuation of seismic phases in the vicinity of the PNPP.

A subset of the Fennoscandian earthquake catalogue (1979-2010; Ahjos and Uski, 1992) is used to approximate the annual number of earthquakes occurring within the PNPP network. The data set represents a time interval with 


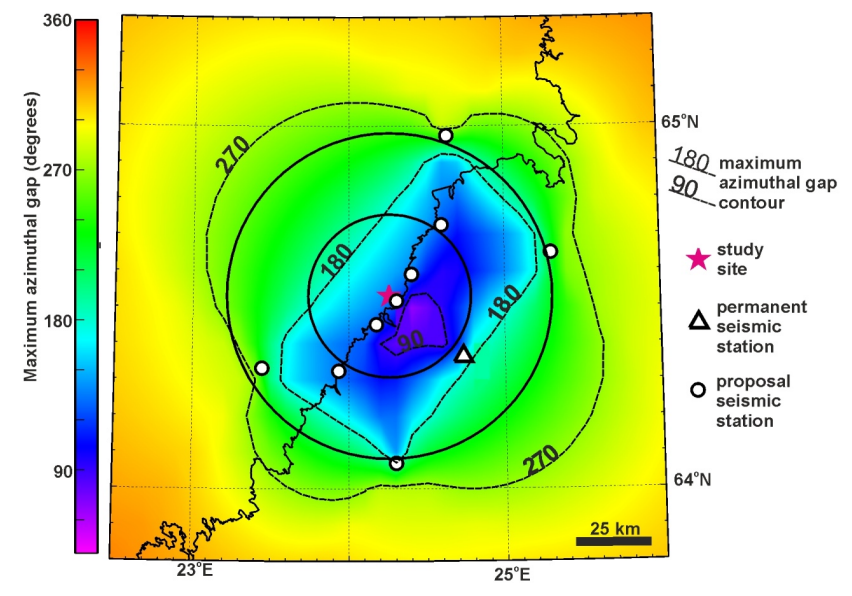

Fig. 4. A map of the maximum azimuthal gap (AG) within a ten station network. Concentric circles around the site show the survey area.

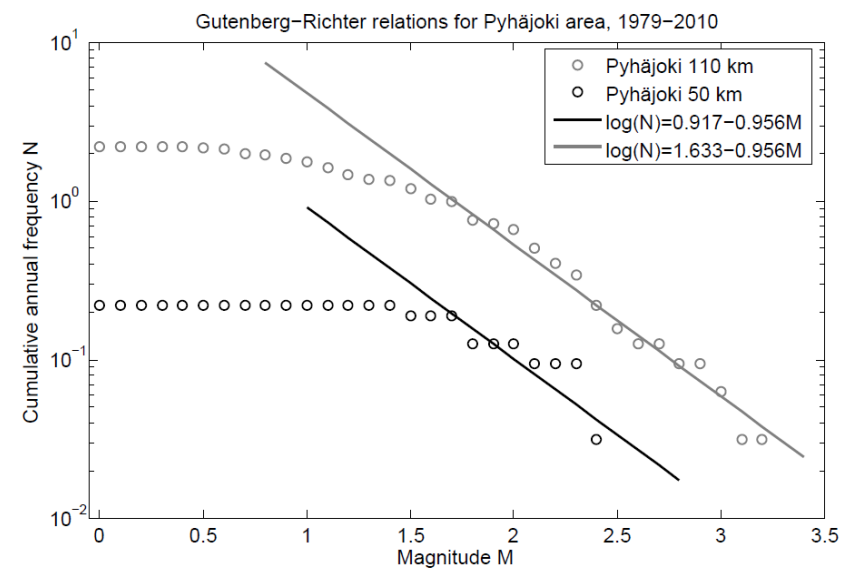

Fig. 5. Magnitude-frequency curves for earthquakes recorded within 110 and $50 \mathrm{~km}$ radius of the study site during 1979-2010. The slope, i.e. the b-value that defines the ratio of small to large earthquakes, determined for the $110 \mathrm{~km}$ data is also applied to the $50 \mathrm{~km}$ data.

consistent magnitude determination as well as an average constant seismicity above $M_{\mathrm{L}}$ of 1.5 (Tiira et al., 2011).

\subsection{Simulation of magnitude threshold and azimuthal coverage}

$\mathrm{P}$ - and S-wave detections from at least three stations are a pre-requirement in the automatic location procedure applied (Tiira et al., 2011). The event-to-station distances define the magnitude of the smallest earthquake that can be located. To simulate the automatic event location capability of the PNPP network, a relation between event magnitude and maximum detection distance of $\mathrm{P}$ - and $\mathrm{S}$-wave pair is required. The data are extracted from the automatic earthquake reports (Fig. 2) and the relation is modelled with the following ground mo-
Table 1. Comparison of simulated networks having 6, 8, 10, 12, and 14 stations. Average threshold magnitude $\left(M_{\mathrm{th}}\right)$ and the area with azimuthal gap (AG) smaller than 90 and 180 degrees are summarized. The area is given as the percentage of the total area (within 25 and $50 \mathrm{~km}$ radius of the PNPP) fulfilling the AG requirement.

\begin{tabular}{lrrrrr}
\hline & 6 & 8 & $10^{*}$ & $12 *$ & $14 *$ \\
\hline$M_{\text {th }} 25 \mathrm{~km}$ & 0.04 & -0.08 & -0.08 & -0.10 & -0.13 \\
$M_{\text {th }} 50 \mathrm{~km}$ & 0.21 & 0.15 & 0.12 & 0.08 & 0.04 \\
AG $\left(90^{\circ}\right) 25 \mathrm{~km}$ & $6 \%$ & $17 \%$ & $17 \%$ & $20 \%$ & $26 \%$ \\
AG $\left(90^{\circ}\right) 50 \mathrm{~km}$ & $1 \%$ & $4 \%$ & $4 \%$ & $5 \%$ & $6 \%$ \\
$\mathrm{AG}\left(180^{\circ}\right) 25 \mathrm{~km}$ & $46 \%$ & $46 \%$ & $89 \%$ & $89 \%$ & $89 \%$ \\
$\mathrm{AG}\left(180^{\circ}\right) 50 \mathrm{~km}$ & $12 \%$ & $27 \%$ & $53 \%$ & $53 \%$ & $53 \%$ \\
\hline
\end{tabular}

* Two island locations included.

tion attenuation formula:

$M=b \log _{10} D+a D+c$,

where $D$ is the maximum detection distance of $\mathrm{P}$ - and Swave pair, $M$ is an event magnitude, $a$ and $b$ are the coefficients of anelastic attenuation and geometrical spreading, and $c$ is a baseline correction.

The data are weighed according to the number of observations in each magnitude class. If least squares method is applied to the data, the following formula is obtained (Fig. 2):

$M=0.9327 \log _{10}(D)+0.001514 D-1.306$.

AG and the threshold magnitude $\left(M_{\mathrm{th}}\right)$ are calculated for different types of station configurations and the results are displayed as contour maps. The maps are calculated by forming a $0.1 \times 0.1$ degree grid over the area. $M_{\text {th }}$ is determined as the magnitude of the weakest locatable event on a given grid point. To ensure that there will be both P- and S-phase detection from at least three stations, we have compiled the maps by using the epicentral distance to the third closest station. The distances are calculated for each grid point and converted to $M_{\text {th }}$ by using Eq. (2).

\subsection{Estimates of earthquake occurrence rate}

The frequency-magnitude distribution is approximated by the Gutenberg-Richter relation (G-R; Gutenberg and Richter, 1944):

$\log _{10} N=a-b M$,

where $N$ is the cumulative number of earthquakes with magnitude equal to or greater than $M$ occurring in a specified space and time window. The intercept $a$ measures the activity rate and the slope $b$ defines the ratio of small to large earthquakes.

By assuming that earthquake self-similarity extends at least down to magnitude $M_{\mathrm{L}} \sim 0.0$ (Abercombie, 1996 and 
references therein), G-R -relation can been applied to estimate the number of micro-earthquakes from the occurrence rate of stronger events (e.g. Häge and Joswig, 2009). The source region must be large enough to include a sufficient number of earthquakes for statistical analysis, but small enough to exclude the neighbouring regions with different seismotectonic characteristics (cf. Fig. 1). We conclude that an area with a radius of $110 \mathrm{~km}$ around the PNPP fulfils the requirements.

\section{Results}

\subsection{Optimal network configuration}

The results of network simulation are presented in Table 1 and Figs. 3 and 4. A minimum of ten seismic stations is required for a network having $M_{\mathrm{th}} 0.0$ or lower and AG smaller than $180^{\circ}$ within $25 \mathrm{~km}$ distance from the study site. The optimal network has two stations situated on islands, which improves both detection and location capability offshore. This results in $M_{\text {th }}$ smaller than 0.0 in most of the study area.

\subsection{Earthquake occurrence rate}

Figure 5 shows the frequency-magnitude distribution of earthquakes located within 110 and $50 \mathrm{~km}$ of the site. The a- and $b$-values within the $110 \mathrm{~km}$ ring are obtained by linear least squares regression analysis with magnitude threshold of $M_{\mathrm{L}} 1.5$. The spatial coverage of seismicity is rather heterogeneous, as only 7 of the 70 events fall within the $50 \mathrm{~km}$ ring (cf. Fig. 1). However, by assuming that the obtained b-value, $b(110 \mathrm{~km})=0.956 \pm 0.197$, is a representative for the whole volume, the activity rate of $a(50 \mathrm{~km})=0.917 \pm 0.762$ is obtained. Those figures predict the annual number of $M_{\mathrm{L}} \geq$ 0.0 earthquakes within the 50 and $25 \mathrm{~km}$ rings to be 8 and 2 , respectively.

\section{Discussion and conclusions}

The results of this study suggests that a minimum of ten seismic stations is required (Table 1; Figs. 3 and 4), if the network is to have the event location threshold of approximately $M_{\mathrm{L}} 0.0$ and the azimuthal gap smaller than $180^{\circ}$ within $25 \mathrm{~km}$ distance from the PNPP. Both island sites are needed to fulfil the requirement. The optimal network is expected to detect 2 and 8 micro-earthquakes $\left(M_{\mathrm{L}} \geq 0.0\right)$ annually within the 25 and $50 \mathrm{~km}$ rings (Fig. 5).
In comparable network setups in seismotectonically comparable areas, the event location accuracy for horizontal coordinates and depth have been estimated to be 1-2 and $4 \mathrm{~km}$ within the network (Korja et al., 2010; Lindblom, 2011; Uski et al., 2012). The optimal network is dense enough to map out capable faults with horizontal precision of $1-2 \mathrm{~km}$ within $25 \mathrm{~km}$ radius of the site. Less detailed information will be acquired on faults within $25-50 \mathrm{~km}$ distance from the site. Unless ocean-bottom seismometers are deployed, focal mechanisms based solely on the PNPP network data may remain ambiguous because the area with azimuthal gap smaller than $90^{\circ}$ is rather limited (Table 1 ).

Acknowledgements. This study is a part of a local seismic network project funded by Fennovoima Oy. We thank the company for support and for the permission to publish this paper.

\section{References}

Abercombie, R. E.: The magnitude-frequency distribution of earthquakes recorded with deep seismometers at Cajon Pass, southern California, Tectonophysics, 261, 1-7, 1996.

Ahjos, T. and Uski, M.: Earthquakes in northern Europe in 13751989, Tectonophysics, 207, 1-23, updated catalogue (13752010), available at: http://www.seismo.helsinki.fi/fi/bulletiinit/ catalog_northeurope.html (last access: 16 April 2013), 1992.

Gutenberg, B. and Richter, C. F.: Frequency of earthquakes in California, Bull. Seismol. Soc. Am., 34, 185-188, 1944.

Häge, M. and Joswig, M.: Microseismic feasibility study: detection of small magnitude events $\left(M_{\mathrm{L}}<0.0\right)$ for mapping active faults in the Betic Cordillera (Spain), Ann. Geophys., 52, 117126,2009 , http://www.ann-geophys.net/52/117/2009/.

International Atomic Energy Agency (IAEA): Seismic hazards in site evaluation for nuclear installations. Specific safety guide SSG-9, Vienna, 60 pp., 2010

Korja, A., Kortström, J., Lindblom, P., Mäntyniemi, P., Uski, M., and Valtonen, O.: Compilation of seismic database and seismic hazard assessment around Pyhäjoki, Geological Survey of Finland, Commissioned research report M210E2010, 38 pp. and 4 appendixes, 2010.

Lindblom, E.: Micro earthquake study of end-glacial faults in northern Sweden, Phil.Lic. Thesis, Department of Earth Sciences, Univ. Uppsala, Sweden, 57 pp., available at: http://www.geofys. uu.se/?q=node/328, 2011.

Tiira, T., Uski, M., Kortström, J., Valtonen, O., and Korja, A.: Pyhäjoki Seismic Network - a Preliminary Proposal, Report T84, Institute of Seismology, University of Helsinki, Helsinki, 37 pp., 201, 2011.

Uski, M., Tiira, T., Grad, M., and Yliniemi, J.: Crustal seismic structure and depth distribution of earthquakes in the Archean Kuusamo region, Fennoscandian Shield, J. Geodyn., 53, 61-80, 2012. 